\title{
TRANSICIÓN, "MODELO" Y GRUPOS ECONÓMICOS AL ALERO DE LAS PRIVATIZACIONES
}

\author{
María Olivia Mönckeberg Pardo
}




\section{MARÍA OLIVIA MÖNCKEBERG PARDO}

Profesora Titular de la Universidad de Chile y Premio Nacional de Periodismo 2009. Fue directora del Instituto de la Comunicación e Imagen de la misma Casa de Estudios por dos periodos, entre 2010 y 2018. Es autora de los libros El saqueo de los grupos económicos al Estado de Chile (2001); El imperio del Opus Dei en Chile (2003); La privatización de las universidades, una historia de dinero, poder e influencias (2005); El negocio de las universidades en Chile (2007); Los magnates de la prensa, concentración de los medios de comunicación en Chile (2009); Karadima, el señor de los infiernos (2011); Con fines de lucro (2013); La máquina para defraudar. Casos Penta y Soquimich (2015), el cual le valió el Premio Municipal de Literatura 2016; y El poder de la UDI. 50 años de gremialismo en Chile (2017). 


\section{TRANSICIÓN, “MODELO”Y GRUPOS ECONÓMICOS AL ALERO DE LAS PRIVATIZACIONES}

Al comenzar el libro La máquina para defraudar. Casos Penta y Soquimich, que publiqué a fines de 2015, recordaba parte de una entrevista en el diario La Época que hice hace casi 30 años a Patricio Aylwin, en ese momento candidato de la Concertación de Partidos por la Democracia y presidente del Partido Demócrata Cristiano. Fue el 21 de mayo de 1989, solo ocho meses después del triunfo del No en el plebiscito, en un ambiente donde había esperanza de que el término de la dictadura generara también cambios sustanciales respecto de todo lo que venía ocurriendo, tanto en el plano político como en el económico.

Conversamos en aquella oportunidad sobre diversos temas, entre ellos de las privatizaciones de las grandes empresas del Estado efectuadas en la segunda mitad de los ' 80 , cuando era ministro de Hacienda Hernán Büchi Buc, quien después fue su contendor en la elección presidencial:

- ¿Cuál es su criterio frente a las privatizaciones? -le pregunté a quien llegaría ser el primer presidente de Chile después de la dictadura.

- No tengo un criterio dogmático al respecto. Creemos que hay empresas que es mejor que sean estatales. Otras es preferible que sean privadas. Creemos, asimismo, que la empresa privada y pública pueden ser igualmente eficientes. Pero la decisión de transferir empresas estatales al sector privado debe corresponder a la voluntad general del país, expresada a través del Congreso, con las debidas garantías del interés público y del patrimonio nacional. Revisaremos -como lo hemos dicho- todas las privatizaciones posteriores al 5 de octubre, porque le negamos al Gobierno representatividad nacional después de haber sido derrotado en las urnas para llevar a cabo una política que compromete gravemente el patrimonio nacional y es repudiada por la mayoría.

- ¿Y las anteriores? -le consulté, aludiendo a todas las privatizaciones que se habían generado en esos años, en particular después de 1985.

- Hubo falta de transparencia y habrá que investigar las condiciones en que fueron realizadas algunas privatizaciones en el pasado. Resulta altamente sospechoso y, por qué no decirlo, escandaloso, que los ejecutivos de empresas estatales que eran los encargados por el Estado de administrarlas, se hayan convertido después de su privatización en sus principales accionistas. Eso, estimamos, merece ser esclarecido. 
No obstante, al final no se hicieron revisiones ni en su mandato ni en los que vinieron. Pasaron los años y los gobiernos de lo que se ha llamado la transición a la democracia. Ni siquiera los escándalos protagonizados en 2015 por dos influyentes grupos económicos como fueron los casos de Penta y Soquimich, sirvieron de remezón para recordar seriamente lo ocurrido con las riquezas del país en estos años.

Fue así como después de tanto camino recorrido en el que hubo estudios de comisiones y poca discusión pública del tema, no se llegó a ninguna iniciativa para revertir la situación de traspaso de los bienes del Estado a manos privadas que había ocurrido bajo la dictadura. Tampoco para generar cambios significativos en el modelo que en ese tiempo se conocía como "economía de mercado" y que resultó ser la más extrema expresión de neoliberalismo, y de aplicación de una estrategia basada en proveer servicios, en la especulación financiera y en la extracción de las materias primas para exportar al exterior.

Los privatizadores desplegaron influencias subterráneas para asentar sus posesiones y fortalecieron sus grupos desde que se hicieron de esas propiedades. Y fue así como se dio, por ejemplo, la gran paradoja de que cuatro nietos de Pinochet, hijos de Julio Ponce Lerou y Verónica Pinochet Hiriart, gracias a todos los hilos que movió el ex yerno del dictador -bajo el régimen de su ex suegro y después-, son hoy los dueños de una de las mayores fortunas del país. Y la forjaron a costa de quedarse con vastas extensiones de tierras y cabezas de ganado, y -en forma muy especialgracias a tomar el control de la Sociedad Química y Minera de Chile, Soquimich, propietaria de grandes yacimientos de minería no metálica y extractora del litio, al que se le ve hoy como el recurso del futuro.

Una muestra del desinterés manifiesto de gobiernos y parlamentarios por revertir la situación en los años de postdictadura es que los estudios de la comisión que se formó en 2014 especialmente para estudiar el presente y futuro del litio quedaron solo en papeles, sin que las recomendaciones llegaran a ningún destino. Mientras, Ponce Lerou y los inversionistas chinos libraban una disputa de alto vuelto por el control del mercado del estratégico mineral. Esta tuvo un punto culminante a fines de este año 2018, cuando Tianqi Lithium, la gigantesca compañía oriental dedicada a la explotación, procesamiento y ventas del preciado recurso, obtuvo más del $24 \%$ de las acciones de la empresa chilena.

\section{EL APURO VENDEDOR}

Ni siquiera los escándalos investigados por los fiscales y conocidos por jueces y autoridades a partir de 2015, que mostraron las redes de influencias y artificios 
utilizados por Ponce Lerou, llevaron a gobiernos o a parlamentarios a poner seriamente en discusión la propiedad de la empresa que le fue adjudicada en esos años '80. Por ese entonces era ministro de Hacienda el mismo Hernán Büchi, quien después lo acompañó por años en el directorio de la empresa.

No es extraño, entretanto, observar que los nombres y personajes protagonistas de aquellos oscuros años dictatoriales se hayan visto en sitios de primer plano durante la transición y se repitan hasta hoy, más de tres décadas después. Al observar el escenario de ayer y el actual se puede apreciar con cierta claridad que el proceso privatizador desplegado en los ' 80 por el régimen militar, además de una operación económica de suculentos beneficios para los compradores, fue una estrategia política destinada a mantener el poder de ciertos grupos, aún después del término del gobierno militar.

No es casual tampoco el apuro vendedor que se vio aquel año '89 después de la derrota de Augusto Pinochet en el plebiscito de octubre de 1988, mientras sus partidarios civiles desplegaban múltiples esfuerzos por dejar todo amarrado para que nada cambiara.

En aquella época la campaña presidencial captaba el interés general. No obstante, continuaron las privatizaciones bajo cuerdas o con poca publicidad, orientadas a fortalecer a esos nuevos grupos que serían básicos para que el "modelo" funcionara.

Unos años antes, a comienzos de la década, los dos grandes conglomerados Cruzat Larraín y Javier Vial, conocidos ambos como los antiguos "pirañas"- habían rodado por los suelos bajo el impacto de la crisis de la Compañía de Refinería de Azúcar de Viña del Mar, CRAV, que los golpeó e hizo tambalear seriamente al sistema financiero local. Era necesario entonces que otros tomaran su lugar.

\section{UN CASO ILUSTRATIVO}

Sin ir mucho más lejos, un caso que ilustra el "tránsito" del poder económico en estos años es el de la próspera "alianza estratégica" forjada por Eduardo Fernández León, el supernumerario del Opus Dei y principal mecenas de la Universidad de Los Andes, y el grupo familiar que encabeza Juan Hurtado Vicuña.

Fue durante ese año 1989, el mismo en que Aylwin había hablado de una posible revisión de las privatizaciones, que los dos socios se beneficiaran con una privatización más que después les daría buenos dividendos: el objetivo fue esa vez la minera Punta del Cobre, una planta de la Empresa Nacional de Minería que fue adquirida entre gallos y medianoche por esta dupla que se caracterizó por una hiperactividad en tiempos de las privatizaciones y que llegó a transformarse en dos poderosos grupos presentes en el escenario chileno de las décadas posteriores: esa 
planta se convirtió en empresa y la empresa en una sociedad anónima que integra la mediana minería del cobre y se transa en la Bolsa de Comercio bajo la sigla Pucobre.

Unos años antes, Fernández León y Hurtado Vicuña se habían quedado con Chilquinta, la compañía eléctrica de la quinta región de Valparaíso, una de las tres en que el ex zar de la electricidad José Yuraszeck dividió a la estatal Compañía Chilena de Electricidad.

Un tiempo después, Hurtado y Fernández León emprendieron otra aventura que les deparó grandes resultados: tomaron el control de la Empresa de Telecomunicaciones, Entel, a principios de 1990, en los primeros días de la transición a la democracia.

Entel fue creada como empresa del Estado en el gobierno de Eduardo Frei Montalva, y su carácter estratégico para las comunicaciones explica que fue una de las últimas en ser privatizadas. A los militares les costó entregarla. Incluso durante la dictadura en ella hubo siempre uniformados a la cabeza, salvo al final cuando el ex ministro de Hacienda Jorge Cauas fue nombrado presidente. Después lo sucedió Hurtado.

En 2001 Entel fue vendida en 500 millones de dólares a la compañía italiana Telecom, lo que implicó un importante negocio para el grupo local, pero cinco años después -en 2006- fue de nuevo adquirida por los mismos socios unidos al grupo Matte, dueño de la Forestal Mininco y la Compañía Manufacturera de Papeles y Cartones, que constituyen el tercer mayor grupo del país, según la revista Forbes. Desde esa fecha Fernández León, los Hurtado y los Matte mantienen el control y Juan Hurtado es el presidente de la empresa.

A la vez, Fernández León y Juan Hurtado son socios en otra compañía muy lucrativa en las últimas décadas, protagonista del floreciente mercado financiero: el Consorcio Nacional de Seguros.

A su vez, Eduardo Fernández León es uno de los más prominentes actores en el negocio inmobiliario y encabeza el ranking de los poderosos en la salud privada: es socio mayoritario del holding Banmédica, que incluye la Isapre del mismo nombre, las Clínicas Santa María, Dávila y Help entre otros servicios a lo largo del país. Y como si fuera poco, destaca en el negocio de la muerte, como socio de los cementerios parque.

A diferencia de Fernández León, que es ingeniero comercial de la Universidad Católica, Juan Hurtado Vicuña y Hernán Büchi fueron compañeros en Ingeniería en la Universidad de Chile. Su amistad viene desde esos años, cuando compartían aulas en Beauchef, aunque Büchi en ese tiempo era un joven izquierdista y Hurtado siempre ha sido de derecha. 


\section{BÜCHI Y SUS HERMANOS}

Hay algunas curiosidades de esa amistad juvenil que tuvieron efectos históricos. Juan Hurtado fue quien presentó al ex ministro de Hacienda a su "colega" Sergio de Castro a principios del régimen militar. Büchi, sin haber sido economista ni estudiado en Chicago, se transformó en el principal ejecutor del modelo económico y social impuesto a sangre y fuego en el país. Desde las sombras a veces, en primer plano otras tantas, Büchi fue impulsor de radicales cambios que afectan hasta hoy la vida diaria de los habitantes de Chile.

Antes de llegar al ministerio de Hacienda en febrero de 1985, Hernán Büchi ya había hecho un recorrido por el gobierno que abarcó las subsecretarías de Economía y de Salud, el cargo de ministro de la Oficina de Planificación Nacional (Odeplan) y la Superintendencia de Bancos.

En dictadura y en las décadas posteriores, la amistad con Juan Hurtado continuó, y se extendió a toda la familia Büchi, al punto de que los hermanos del ex ministro han sido hasta ahora directivos de confianza del grupo Hurtado Vicuña.

Richard Büchi Buc es miembro del directorio de Entel y Antonio, el menor de la familia, su gerente general. A su vez, Marcos Büchi Buc pasó a ser el presidente del Consorcio Financiero - del cual depende el Consorcio Nacional de Segurosdespués que Juan Bilbao, el antiguo hombre de confianza de Hurtado y Fernández León, cayó en desgracia por los turbios manejos que efectuó en compraventa de acciones, lo que le costó un juicio y elevada sanción en Estados Unidos.

Entre otras actividades, desde 2009 Juan Hurtado es el presidente de la Corporación Santo Tomás, la que adquirió tras la muerte de Gerardo Rocha. La Corporación reúne a la universidad de ese nombre, un instituto profesional y un centro de formación técnica que están entre los más numerosos y lucrativos de la educación superior privada. En esa actividad también lo acompañó Marcos Büchi como director ejecutivo de la Corporación Santo Tomás, antes de ser nombrado presidente del Consorcio Financiero.

\section{EL EX MINISTRO GUZMÁN MOLINARI}

En 2015 el terremoto que afectó a partidos políticos y algunos grupos económicos al destaparse los casos Penta y Soquimich llevó a Hernán Büchi a renunciar al directorio de Soquimich. También dejó su cargo en la presidencia de la empresa otro antiguo conocido de esos tiempos: Juan Antonio Guzmán Molinari, el ex ministro de Educación de Augusto Pinochet cuando José Luis Federici fue rector delegado de la Universidad de Chile. Antes había sido vicepresidente de la Comisión Nacional 
de Ciencia y Tecnología (Conicyt). Ingeniero industrial químico de profesión, fue profesor en la Universidad Católica de varios de quienes después llegaron a cargos directivos en la privatizada Soquimich.

Guzmán Molinari ha mantenido una posición prominente en ámbitos empresariales y de educación superior. Tuvo un papel clave tras el virtual regalo de Inacap que le efectuó la Corfo en 1989 a la Confederación de la Producción y del Comercio. Y es desde hace años presidente de la Universidad Andrés Bello del polémico grupo Laureate y -a la vez- de la Clínica Indisa. Uno de sus grandes amigos desde los tiempos de la Escuela de Ingeniería de la Universidad Católica es el ex presidente de la Sociedad de Fomento Fabril, Bruno Philippi -cuñado de Cristián Larroulet-. Junto a él fue protagonista de la privatización de la eléctrica Gener y después su gerente general mientras Philippi era presidente.

Entre sus amigos y socios figura también el ex subsecretario de Economía de Salvador Allende, Óscar Guillermo Garretón. A la vez, en 2008 Guzmán Molinari se involucró en el negocio de los estacionamientos y controla el 33\% de Central Parking System. Entre otras actividades, además es director de Sonda y presidente de la empresa Extend Comunicaciones.

\section{SÍNTOMA Y SÍMBOLO}

Apenas alcanzaron a pasar tres años cuando en abril de 2018 Hernán Büchi volvió a acompañar a su antiguo amigo Julio Ponce Lerou en el directorio de la empresa. Esta vez junto a otro connotado personaje también amigo y ex socio de Guzmán Molinari, que estuvo en tela de juicio por el caso de las boletas y facturas: Laurence Golborne, el ex ejecutivo del retail y ex ministro de Minería de Sebastián Piñera en su primer gobierno; el mismo que se hizo famoso con el rescate de los 33 mineros y después soñó con ser Presidente de la República, pero se vino abajo su proyecto cuando se revelaron sus inversiones en paraísos fiscales.

Dotado de una suerte de omnipresencia en los directorios y posiciones decisivas, Hernán Büchi declaró hace tres años que se iría a vivir a Suiza debido a la "incerteza jurídica” que, según él, había en Chile. Pero al parecer se las arregla para venir una semana al mes y figura en diversas actividades, casi como un símbolo del devenir de los ex ejecutivos de la dictadura y del poder que han mantenido y acrecentado en este tiempo los grupos económicos forjados a su alero.

A su amistad y sus negocios con su antiguo amigo Juan Hurtado y a la participación en la empresa controlada por Ponce Lerou, Hernán Büchi suma una decena de directorios y también la propiedad accionaria en algunas actividades. Pero ha sido su compromiso con el Instituto Libertad y Desarrollo (LyD), el centro de 
estudios ligado a la UDI y soporte vigilante del modelo económico, una de sus preocupaciones.

Después de perder la elección presidencial de marzo de 1990, una de las primeras actividades en que se embarcó fue crear junto al ex ministro de Hacienda e Interior de Pinochet, Carlos Cáceres, esa instancia que ha sido clave en el diseño de políticas públicas, impulsora de ideas, estudios y proyectos, con un rol fundamental en la asesoría parlamentaria de los senadores y diputados de ese sector de la derecha.

Desde su nacimiento en marzo de 1990, el director ejecutivo de LyD fue Cristián Larroulet Vignau, el jefe de gabinete de Hernán Büchi cuando era ministro de Hacienda. Larroulet desempeñó ese cargo hasta que fue nombrado ministro Secretario General de la Presidencia en el primer gobierno de Sebastián Piñera. Estuvo ahí todo el periodo. Se instaló después en la Universidad del Desarrollo, para volver en la segunda administración de Piñera con un cargo muy similar pero tras bambalinas: es el jefe de los asesores del "segundo piso", uno de las más influyentes voces en La Moneda. Economista de la UDI forjado en la Universidad Católica, en la escuela de Sergio de Castro y de Miguel Kast, Larroulet es uno de los más significativos vigilantes del modelo económico y político hasta hoy.

La preocupación de Larroulet por influir con sus ideas se manifestó en otra iniciativa que empezó justo en febrero de 1990, cuando terminaba la dictadura: la creación de la Universidad del Desarrollo junto a sus amigos Joaquín Lavín Infante -hoy alcalde de Las Condes-, Ernesto Silva Bafalluy -quien murió en agosto de 2011- y Federico Valdés Lafontaine, actual rector de esa universidad y uno de los máximos defensores de los beneficios estatales para las universidades privadas.

Al poco tiempo se sumaron a esa aventura educacional Carlos Eugenio Lavín y Carlos Alberto Délano, los conocidos dueños del grupo Penta, y el propio Hernán Büchi.

Aunque tras el escándalo que los llevó a la cárcel y a ser sancionados por la justicia Lavín y Délano salieron del primer plano, hoy por hoy son ellos los verdaderos dueños de la Universidad del Desarrollo. Son los propietarios de la inmobiliaria Ainavillo, dueña de los edificios, y en el directorio de la Corporación están representados por sus hijos y algunos amigos como Fabio Valdés Correa. Quien preside la Universidad del Desarrollo no es otro que Hernán Büchi, accionista también de la inmobiliaria,

Los lazos de Hernán Büchi no terminan ahí. Es miembro del directorio de Quiñenco S.A., la matriz del grupo Luksic que actualmente encabeza el ranking del poder en Chile. A la vez, el ex ministro de Pinochet es asesor del Banco de Chile, controlado por el mismo grupo.

En pocas palabras, se podría decir que este personaje es síntoma y símbolo de lo ocurrido en Chile en estos años donde él fue desde los primeros tiempos de 
dictadura uno de los impulsores y ejecutores del modelo que se impuso y se ha perpetuado y sobrevivido a crisis y escándalos.

\section{SECUELAS Y RAÍCES}

Al observar el panorama hoy, 30 años después del legendario triunfo del No en el plebiscito, seguido en 1989 de la primera elección presidencial, se puede concluir que las profundas reformas neoliberales fueron mucho más extremas de lo que el más visionario habría esperado.

Cuando Augusto Pinochet dejó La Moneda en marzo de 1990 se produjo un clima de alivio y esperanza. La opresión de vivir 17 largos años en dictadura quedaba atrás. Se respiraba aire de libertad y eso era fundamental. También es cierto que en los años posteriores el país creció, que disminuyó la pobreza y que las políticas públicas tuvieron un sentido más social. Pero también lo es que la desigualdad y la estratificación social se fueron acentuando y que los problemas sin resolver se multiplicaron.

Si se observa con más detención, se podría concluir que los fuertes y constantes reclamos que se manifestaron desde 2011 -cuando estalló el movimiento estudiantil que cambió la agenda de discusión de las demandas y políticas públicas- tienen que ver con el modelo dictatorial cuyas directrices se viven hasta hoy. Lo ocurrido en educación, en salud, en previsión social, en relaciones del trabajo son sus derivaciones. El deterioro de la educación pública y las protestas de los estudiantes y profesores; las paupérrimas pensiones que entregan las Administradoras de Fondos de Pensiones (AFP) a los que prometieron hace 30 o 40 años jubilaciones fabulosas; los innumerables problemas de la salud pública y los abusos de las Instituciones de Salud Previsional (Isapres) y de quienes controlan las clínicas privadas son parte de las duras secuelas de ese modelo impuesto contra la voluntad y a espaldas de la ciudadanía.

En un periodo más reciente se puede constatar que otras demandas y protestas de corte medioambiental, por ejemplo, están estrechamente relacionadas con ese modelo impuesto al amparo de la fuerza en dictadura, pero que en sus rasgos centrales se perpetuó en la transición y no se ha logrado cambiar sustancialmente.

Y si se trata de comprender lo que está sucediendo en La Araucanía también se podría encontrar en el trasfondo la raíz económica de un modelo basado en explotar las riquezas básicas, que no respeta tierras ni derechos de agua. Los reclamos contra las empresas forestales, encabezadas por Mininco, del grupo Matte, o contra las poderosas hidroeléctricas son elocuente muestra de que muchas comunidades y organizaciones así lo viven y lo sienten. 
Después del golpe, el gobierno militar devolvió a sus antiguos dueños bancos, empresas y fundos por doquier. Y vendió lo que tenía en sus manos al mejor postor. Dio rienda suelta al endeudamiento en el exterior y alentó el negocio financiero. La creación de un mercado de capitales activo pasó a ser una prioridad de la que se hablaba mucho mientras algunos grupos -sobre todo los que contaban con simpatías del régimen- coleccionaban empresas y deudas. Por esos años se puede encontrar el germen de la economía especulativa y basada en la exportación de recursos naturales que tan habitual se hizo después, mientras se derrumbaban las industrias y el concepto de "valor agregado" quedaba en el olvido.

Por esos años también se achicó el rol del Estado hasta su mínima expresión, ensalzando la propiedad privada y el mercado mientras se violentaban derechos y vidas de cientos y miles de personas. Hoy parece claro que sin la brutal represión de los años '70 y '80 los economistas no habrían podido implantar un modelo tan extremo como el que instalaron.

\section{EL ENTRAMADO Y SUS AMARRAS}

Al observar en perspectiva se puede apreciar que todo el entramado político que se fue construyendo bajo la batuta del fundador del gremialismo, Jaime Guzmán Errázuriz, iba en estrecha relación con el modelo económico y social que se impuso. La Constitución de 1980, aprobada en un fraudulento plebiscito sin discusión masiva y abierta, logró en buena medida su objetivo de prolongar en el tiempo un estado de cosas antidemocrático y adverso a las grandes mayorías. La democracia tutelada o semisoberana de la que habla el cientista político Carlos Huneeus sigue tan vigente como en los primeros años del postpinochetismo. ${ }^{1} \mathrm{El}$ caso del Tribunal Constitucional y sus facultades es un ilustrativo ejemplo de una de las pesadas herencias, pero no el único.

La propia Constitución exalta la propiedad privada como el máximo valor de una sociedad en la cual las personas, más que ciudadanos, se han convertido en consumidores. Todo en ella está impregnado de esa concepción de "Estado subsidiario" y visión economicista y privatista.

Las leyes orgánicas constitucionales, que en los diferentes sectores complementaron los diseños de la Constitución, fueron también pensadas y dispuestas en esta misma línea para asegurar que nada se apartara de ese modelo. Con sus elevados quórums para modificarlas han mostrado cuán rígidas pueden ser las amarras que dejaron puestas quienes ejercieron el poder dictatorial. Y no es lo

1. Carlos Huneeus. La democracia semisoberana. Chile después de Pinochet. Taurus, 2014. 
único. El Código de Aguas, el de Minería y tantas otras creaciones de ese tiempo han sido complementos importantes de ese modelo que ha favorecido de manera ostensible a una abrumadora minoría de la población.

Y si faltaban leyes, también hubo simplemente decretos ad hoc, reformas escondidas y de emergencia para pasar por legal lo que no lo era.

Una pieza clave de todo este edificio fue el sistema electoral binominal que se estableció en mayo de 1989, antes de la primera elección de parlamentarios -se efectuó en diciembre de ese año junto a la presidencial. Fue ideado por los asesores de Pinochet para que no se pudieran elegir más de dos diputados o senadores por distrito a agrupación senatorial, ya que un diputado o senador para ser electo tenía que contar con más del 33,3\% de los votos; en esas condiciones, duplicar esa cifra para una coalición resultaba una tarea titánica. Y era fácil ser elegido con un 34\%.

El binominal, pese a las controversias que suscitó desde el comienzo y a los proyectos por modificarlo que se presentaron durante años -siempre rechazados por la UDI-, finalmente terminó 24 años después, en enero de 2015, justo cuando reventaban los líos entre dinero y política que implicaron primero al grupo Penta y luego a Soquimich y a connotadas figuras del espectro político.

Las primeras elecciones que se efectuaron sin el sistema binominal en noviembre de 2017 mostraron significativos cambios, con la entrada en el escenario del Frente Amplio. Pero está a la vista que eso no basta aún para hacerle mella significativa al modelo económico. Menos aún si no se logran acuerdos en la oposición y si no existen medios de comunicación capaces de dar sustento a una vida democrática que permita conocer las distintas realidades y problemas y dar espacio al debate necesario y plural.

\section{OTROS EFECTOS DE LA OLA}

En el citado libro La máquina para defraudar comentaba que los financiamientos "legales o escondidos de empresas para campañas políticas que saltaron al ruedo público gracias a las investigaciones de los fiscales llevan a pensar que en Chile se ha vivido en estos años una democracia 'hipotecada'. Si se tira un poco la cuerda se podría pensar que en este escenario político bien dibujado por quienes lo impusieron han sido muchos los que han 'comprado' sus sillones parlamentarios: las dádivas de los controladores de las grandes empresas les han permitido llegar en cada ocasión a los ciudadanos con sus mensajes difundidos a través de medios de comunicación... y en muchas ocasiones con regalos y promesas de todo orden. Las campañas son caras y requieren endeudamiento. Todo eso ha tenido su precio".

Tan fuerte como esas amarras ha sido el impacto durante todos estos años del poder económico. Lo paradójico es que ese poder, fortalecido en un comienzo bajo 
dictadura y que se continuó desarrollando después, se originó en parte importante en lo que se le despojó al Estado a través de privatizaciones de empresas, subsidios, créditos y diferentes tipos de dádivas.

Otro factor decisivo fue la creación de las hoy controvertidas Administradoras de Fondos de Pensiones (AFP), que generó el traslado de los fondos de los trabajadores a manos de grupos privados en 1981. Y cuando tras la crisis de 1982 los bancos sucumbieron, para evitar la quiebra y el colapso total, el Estado, aparte de respaldar a las AFP y otras empresas que pasaron a la denominada "área rara", estableció subsidios a los bancos comerciales a través de complejos mecanismos que evitaron su caída y les permitieron seguir funcionando y haciendo negocios.

Las grandes empresas del Estado, consideradas estratégicas para el desarrollo del país, fueron factor clave para que se consolidaran nuevos grupos, como concluyó el informe sobre las privatizaciones llevadas a cabo entre 1973 y 1990 efectuado por una comisión especial de la Cámara de Diputados en 2005, que presidió el hoy senador Carlos Montes. También ese informe considera otras "reprivatizaciones" de las empresas que fueron traspasadas después de la hecatombe de los '80. Sin todo ese sustento no habrían logrado amasar las grandes fortunas que ostentan muchos de los connotados magnates de hoy.

Esa ola privatizadora que sobrevino después de la crisis de 1982 también significó la consolidación para grupos de corte más tradicional como los Matte o Anacleto Angelini, que se quedaron con parte de lo que había pertenecido al grupo Cruzat-Larraín, como las empresas forestales y de celulosa que fueron creadas por el Estado. Y Andrónico Luksic, que logró la Compañía de Cervecerías Unidas (CCU) y luego continuó con Madeco, el Banco de Chile y la actividad minera.

Como se ha visto, al compás de esos traspasos de grandes compañías en la dictadura, la economía se fue concentrando cada vez más. Pero este fenómeno continuó después de los años '90, durante la transición.

En algunos rubros, como las sanitarias y los puertos, que en dictadura se habían librado del traspaso, el impulso fue retomado tras los primeros años del cambio de régimen. En el gobierno de Eduardo Frei Ruiz-Tagle se vendieron las sanitarias, en mejores condiciones que las transacciones de tiempos de Pinochet, según se argumentaba, y se privatizaron las faenas de la mayoría de los puertos.

El planteamiento de fondo era la falta de recursos del Estado y las necesidades de inversión. Lo mismo ocurrió en el gobierno de Ricardo Lagos con las concesiones de obras públicas. También es lo que está detrás del crecimiento sin límites -ni regulación- que tuvieron en esos años las universidades privadas, las que han sido favorecidas con recursos del Estado que se les otorgan por la vía del subsidio a la demanda representado por el interés de los estudiantes que acuden a ellas, a quienes se les dan créditos o becas. El Crédito con Aval del Estado (CAE), que 
data de 2006, es un elocuente ejemplo de la canalización de recursos del Estado a las universidades privadas que ha permitido la notable ampliación de matrícula en entidades privadas que no dan garantías de calidad, y que ha comprometido gran cantidad de recursos fiscales.

\section{SIN PRIORIDAD}

En los días tempranos de la transición a la democracia se hicieron algunos estudios y tiempo después de asumir el primer Parlamento postdictadura hubo un par de comisiones en la Cámara de Diputados que pretendieron dar una mirada a las irregulares privatizaciones de las ex empresas del Estado. Pero al final no se materializaron en proyectos legislativos ni en iniciativas del Ejecutivo en esa tensa y atemorizada etapa de transición a la democracia inaugurada en marzo de 1990 con Aylwin en la presidencia.

Hay quienes afirman que dentro de los denominados "pactos de la transición" se habrían efectuado negociaciones entre representantes de Pinochet con los líderes de la Concertación para no tocar nada de lo ya hecho. Y que la gigantesca transferencia de recursos que se efectuó a espaldas de la ciudadanía silenciada y reprimida fue uno de los altos precios que se pagaron para que el dictador y sus seguidores devolvieran el poder político y abandonaran La Moneda. Pero como suele ocurrir en situaciones así, de eso no hay huellas, no hay documentos, no hay firmas que lo corroboren. Tampoco -al menos nadie lo ha confesado- actores de ese supuesto acuerdo que digan "yo estuve en esa conversación" o "yo pacté" o, al menos, "fui testigo".

Desde otra perspectiva, con el transcurrir del tiempo algunos protagonistas de esos días han reconocido que cambiar el modelo económico no era prioritario.

El cientista político Carlos Huneeus, en su mencionado libro La democracia semisoberana (2014), indica que cuando diputados de la Concertación pidieron constituir una comisión investigadora sobre la venta de las empresas públicas, esta fue detenida por decisión de La Moneda, por iniciativa del entonces ministro Secretario General de la Presidencia Edgardo Boeninger.

Muchos que no vivieron esos tiempos o que eran aún niños o muy jóvenes preguntan por esa época. “¿Cuál fue la razón para que no se revisaran y se dejara el escenario como lo marcó la dictadura?" “Cómo pudieron quedar en la impunidad los que se enriquecieron de manera descomunal en forma tan poco ética?”.

Parte de las respuestas está en el clima de fragilidad que se vivía en los primeros años de esa transición amenazada por "ejercicios de enlace" y "boinazos", mientras Pinochet se mantenía en su sitial como comandante en jefe del Ejército.

Es posible pensar que los elocuentes "gestos militares" que marcaron el comienzo de los '90 hayan influido para no dar prioridad a algo que clamaba por 
ser revisado, como las privatizaciones de las empresas del Estado. Y numerosos y cuantiosos negociados que quedaron en la impunidad.

En ese clima, personajes cercanos a Pinochet, como su ex yerno Julio Ponce Lerou, que se había quedado -además de otras propiedades- con la Sociedad Química y Minera de Chile (Soquimich), se sentían aún intocables. Otro tanto ocurría con partidarios acérrimos del general, como los controladores del grupo Penta, Carlos Alberto Délano y Carlos Eugenio Lavín, quienes tenían estrechísimos lazos con la UDI. O con muchos de los demás privatizadores.

Cuando se produjo el cambio de régimen en ese ambiente contaminado por el temor y los traumas por lo vivido, los vientos estaban sin duda a favor del empresariado partidario del golpe militar y de quienes se transformaron en empresarios y en poseedores de fortunas gracias a los anómalos procesos de las oscuras operaciones ejecutadas en el régimen militar.

Pero antes del denominado "ejercicio de enlace", ya en octubre de 1990, el entonces vicepresidente de la Corporación de Fomento (Corfo), el abogado radical René Abeliuk -quien murió en noviembre de 2014-, manifestó: "No se revertirán las privatizaciones", como se puede leer en el título de una entrevista publicada por la revista Hoy. En esa entrevista Abeliuk se mostró partidario de no revertir las privatizaciones, pese a la "gruesa pérdida estatal", porque "son juicios complejos que tomarían mucho tiempo y el resultado para la empresa sería que quedaría en una situación incierta que la paralizaría. Mi recomendación sería no iniciar este tipo de procesos, no atacar a la empresa, sino buscar la sanción a la empresa que actuó mal”. Eso jamás ocurrió.

El mismo Abeliuk señaló que los cambios en el modelo económico no constituían por esos días algo prioritario.

\section{"UNA REVOLUCIÓN CAPITALISTA RADICAL"}

No obstante, en el primer Congreso al inicio de la transición surgió la inquietud por esclarecer lo ocurrido con las privatizaciones durante el periodo dictatorial. Para tratar de establecer los hechos se constituyó en la Cámara de Diputados una comisión que tuvo un largo nombre y una corta vida: "Comisión especial investigadora de la anterior administración de la Corporación de Fomento de la Producción y las privatizaciones de las empresas filiales". La presidió el ex diputado socialista Armando Arancibia, y el objetivo era "investigar la pérdida patrimonial experimentada durante el Gobierno militar, y causada por la privatización de las empresas estatales, el servicio de las deudas, el otorgamiento de créditos sin garantías, las donaciones de patrimonio físico, la condonación de deudas a terceros y las múltiples formas de subsidio al sector privado que allí se desarrollaron", según 
dice el informe de la segunda comisión, la que años más tarde presidió el entonces diputado también socialista Carlos Montes.

Pero esa primera comisión presidida por Arancibia se disolvió sin entregar un resultado público. Se guardaron los documentos recopilados y pasó más de una década hasta que volvieran a ser analizados.

"Lamentablemente, ruido de sables impulsados por el general Augusto Pinochet Ugarte obligó a dicha comisión a interrumpir abruptamente su cometido", indica el texto del informe de su sucesora, constituida más de una década después. Esta heredó diecisiete volúmenes de fotocopias, documentos probatorios y análisis en los archivos de la Cámara de Diputados en los que había avanzado la primera, "algunas conclusiones valiosas y muchas interrogantes", según el informe.

Los documentos recopilados en 1991 fueron desclasificados en 2004 y 2005, cuando se inició el trabajo de la comisión presidida por Carlos Montes, quien fue elegido en 2013 senador por Santiago Oriente y luego ha sido presidente del Senado.

Esta segunda comisión también estuvo precedida de un largo título: se la llamó "Comisión encargada de investigar presuntas irregularidades en las privatizaciones de empresas del Estado ocurridas antes de 1990” y sesionó hasta 2005.

Entre otros, participaron en ella los diputados Jorge Burgos, quien después fue ministro del Interior; Adriana Muñoz, hoy senadora del Partido Socialista por la región de Coquimbo; el ex diputado DC Eduardo Saffirio, y el ex diputado de la UDI Julio Dittborn Cordua, ex subsecretario de Hacienda de Sebastián Piñera y ex presidente de la UDI.

Fui invitada a esa comisión para aportar antecedentes a partir de lo que había publicado en el libro El saqueo de los grupos económicos al Estado chileno, editado en 2001. La exposición quedó consignada en el informe final de esa instancia parlamentaria.

En total fueron casi 20 personas las que desde distintas ópticas colaboraron con el panorama que pudo llevar a la comisión a sus conclusiones ${ }^{2}$. Asimismo, se requirió información documental y estadística a organismos públicos, tales como la Contraloría General de la República, la Corporación de Fomento de la Producción,

2. Entre los invitados que entregaron testimonio en la comisión estuvieron Armando Arancibia, ex diputado que presidió la primera Comisión en 1991; los ex vicepresidentes de Corfo René Abeliuk y Óscar Landerretche; Carlos Mladinic, ex gerente del Sistema de Empresas Públicas; Rolf Lüders, ex biministro de Hacienda y Economía del gobierno militar y profesor de la Universidad Católica de Chile; Rosanna Costa, en representación del Instituto Libertad y Desarrollo; los economistas Mario Marcel, director de Presupuesto en el tiempo en que funcionó la Comisión; Manuel Riesco, director del Centro de Estudios, Cenda; Ricardo Ffrench-Davis, profesor de la Universidad de Chile; el sociólogo Fernando Dahse, profesor de la Universidad Católica; el ex fiscal de Corfo Guido Machiavello; el abogado Sergio Fuenzalida, y dirigentes sindicales. 
el Ministerio de Bienes Nacionales y la Superintendencia de Valores y Seguros, entre otros.

En la ocasión se convocó también a entregar su testimonio a los principales privatizadores: Hernán Büchi, Julio Ponce Lerou y Roberto de Andraca, el que se privatizó con la CAP. Ninguno de ellos acudió.

En sus conclusiones, el informe de esa comisión investigadora que no fue aprobado por los parlamentarios de oposición y que a la larga quedó en el olvido, señala: "El objetivo estratégico de los sectores que dirigieron el proceso 73-90 fue imponer un cambio estructural que transfiriera el poder a un nuevo grupo que se conformaría con los grupos económicos que habían venido formándose en Chile".

El documento, dado a conocer en agosto de 2005, agrega que esa nueva clase se forjó con "los tecnócratas del régimen que diseñaron las privatizaciones y también se apropiaron del patrimonio público, como dueños de las empresas o ejecutivos poseedores de paquetes controladores de acciones". En otras palabras -dice-, durante el periodo 1973-1990 en Chile se desarrolló "una revolución capitalista radical que transformó estructuralmente la sociedad chilena, llevándola a romper de raíz con la historia republicana y la tradición democrática que la habían caracterizado hasta 1973".

Coincidieron los diputados de la Concertación en que "el proceso privatizador implementado es totalmente inviable en una sociedad democrática con instituciones sólidas".

La "gran obra" de Pinochet provocó el mayor traspaso de poder y de recursos desde el Estado al sector privado del que se tenga memoria en la historia republicana.

El documento final de la comisión de las privatizaciones habla de la creciente concentración de la propiedad en grupos económicos poderosos, "algunos de los cuales se encuentran en los rankings de Forbes entre los más ricos del mundo". Mientras, la distribución del ingreso en el periodo -destacan los parlamentarios"fue la más desigual de la historia de Chile". La participación del quintil más pobre de la población en el gasto se redujo de 7,6\% en 1969 a 4,4\% en 1988. Por eso, aseguran en el informe, "el nuevo modelo no solo se construyó a costa del patrimonio público, sino sobre la base del despojo de amplios sectores medios y populares, cuya situación ha sido imposible de superar hasta hoy".

El mismo documento resume que entre 1973 y 1990 se enajenaron y devolvieron 725 empresas. Dentro de ellas había 124 “calificadas como las más grandes” y 46 eran estatales desde antes de 1973. Anota también que 25 empresas fueron "enajenadas con urgencia después del plebiscito de 1988”. Señala que 43 del total pertenecían a la denominada "área rara", esto es, las que volvieron al Estado tras la debacle de 1983. Y según el informe de la Comisión, 35 de ellas fueron "doblemente subsidiadas por el Estado al ser dos veces privatizadas". 
Al leer con detención ese documento se corroboran esos elementos que marcaron la transición desde el punto de vista económico. Y se puede entender mejor por qué el modelo económico se tornó prácticamente intocable. 30 años después se viven las consecuencias de lo sucedido en dictadura. De lo diseñado y lo aplicado para que perdurara.

Se puede apreciar así que los tradicionales grupos económicos y los que se forjaron en ese tiempo de opresión, aquellos civiles del dictador que hicieron junto a él posible su revolución económica o contrarrevolución -según el cristal con que se mire-, han gozado y la mayoría sigue gozando de elevadas posiciones en el mundo de los negocios y las finanzas.

Si hoy se revisan archivos y registros, se observa que muchos de los ex ministros y colaboradores de Pinochet encabezan grupos económicos y financieros; son parte de directorios de bancos, de AFPs, ex empresas del Estado, de Isapres, clínicas y compañías de seguros, o despliegan lucrativos negocios inmobiliarios y agrícolas. Y son dueños o participan de las juntas directivas de algunas de las más importantes universidades privadas.

A través de su accionar y de las amarras constitucionales y jurídicas que instalaron junto al dictador, estos personajes lograron perpetuar y acrecentar sus riquezas y su influencia. Durante la transición siguieron aumentando el poder económico conquistado en la dictadura. Y son actores decisivos 30 años después. 